\title{
Dinâmicas sub-regionais e expressões metropolitanas na Amazônia brasileira: olhares em perspectiva
}

\section{Sub-regional dynamics and metropolitan expressions in the brazi- lian Amazon: looks in perspective}

Tiago Veloso - Universidade Federal do Pará (UFPA). Mestre em Geografia. Doutorando em Desenvolvimento Sustentável; Núcleo de Altos Estudos Amazônicos (NAEA)/Universidade Federal do Pará (UFPA). E-mail: tiagoveloso2003@yahoo.com.br

Saint-Clair Cordeiro da Trindade Júnior - Doutor em Geografia Humana; Núcleo de Altos Estudos Amazônicos (NAEA)/Universidade Federal do Pará (UFPA). E-mail: stclair-jr@hotmail.com stclair@ufpa.br

\section{Resumo}

Dentre os elementos que marcam o fenômeno urbano na Amazônia, destaca-se o processo de metropolização das grandes cidades. Tal processo, entretanto, não se caracteriza necessariamente por aquilo que poderia revelar uma possível particularidade em nível macrorregional. A configuração de uma fronteira econômica que se expande de forma desigual e diferenciada no interior da Amazônia é responsável também pela formação de distintas sub-regiões. As metrópoles que aí se formaram são produto, condição e meio desse movimento de diferenciação, que pode ser exemplificado através das aglomerações de Belém, Manaus e São Luís, integrantes do complexo regional amazônico. Considerando, dentre outros elementos, a relação que estabelecem com a região e a forma de institucionalização das mesmas, busca-se mostrar a importância e o significado dessas formações metropolitanas em face de processos diferenciados de produção do espaço em curso na região.

\section{Palavras-chave}

Amazônia. Metropolização. Urbanização Concentrada. Sub-regiões. Fronteira Econômica.

\begin{abstract}
Amongst the elements that mark the urban phenomenon in the Amazon, it is highlighted the process of metropolization of big cities. Such a process, however, is not necessarily characterized by what could reveal a possible particularity in a macro-regional level. The configuration of an economical boundary that spreads in an unequal and differential rate in the Amazon inland is also responsible for the formation of distinct sub-regions. The metropolis that have been established there are product, condition and way to this movement of differentiation that may be exemplified by the agglomerations of Belém, Manaus and São Luis which integrate the Amazon regional complex. Considering, amongst other elements, the relationships that they have with the region and the form of their institutionalization, it is aimed to show the importance and significance of these metropolitan formations as for the differentiated processes of production of space that are happening in such a region.
\end{abstract}

\section{Keywords}

Amazon. Metropolization. Concentrated Urbanization. Sub-regions. Economical Boundary. 


\section{INTRODUÇÃO}

Rios, rodovias, ferrovias, unidades de conservação, reservas extrativistas, novas unidades municipais, grandes projetos econômicos e de infraestrutura, sistemas portuários modernos e outros elementos têm caracterizado a densidade e a diversidade socioterritorial do espaço amazônico nos últimos tempos, definindo aquilo que Becker (2001) denominou de malha técnico-política e de malha socioambiental da Amazônia.

Essas malhas, sobrepostas nas últimas décadas, têm sido responsáveis também por uma dinâmica de diferenciação intrarregional crescente que repercute no processo de urbanização em curso e na definição e configuração de espaços metropolitanos que estão diretamente associados aos perfis sub-regionais dos quais fazem parte. Trata-se de uma tendência que acompanha processos que se vêm apresentando no Brasil como um todo, em cujo contexto territorial emerge uma realidade urbana e metropolitana que é complexa e dinâmica. Essa realidade apresenta-se como fenômeno socioespacial relativamente recente, embora reafirmando problemas estruturais presentes há algum tempo na urbanização brasileira.

Nesse caso, pode-se afirmar que, mesmo com maior difusão na extensão territorial do país, a urbanização tem ainda nas metrópoles os principais focos de sua concretização e projeção. $\mathrm{O}$ tamanho e a expressão em aspectos diversos dessas aglomerações urbanas revelam uma face importante da dinâmica socioespacial brasileira, que é a concentração demográfica em pouco mais de uma dezena de epicentros nacionais e regionais. Particularmente no caso da Amazônia brasileira, foco da presente análise, é necessário atentar para o fato de que parcelas significativas dessa região acompanharam, nas últimas décadas, as tendências de urbanização, e mais recentemente de metropolização, verificadas no território nacional.

Os processos de indução de urbanização em diversas escalas do ambiente regional foram amplamente incentivados na Amazônia a partir dos anos 1960, visto que constituíam a base territorial urbana de um projeto de integração da região à economia e ao território brasileiro. Ainda assim, pensados pela lógica unificadora da integração, esses processos assumiram diferentes contornos, o que resultou em uma urbanização diversificada, ainda que inserida em um mesmo contexto regional.

A constituição de um conjunto de aglomerados metropolitanos tem-se tornado significativa na Amazônia brasileira, acompanhando o desenvolvimento Novos Cadernos NAEA • v. 17 n. 1 • p. 177-202 • jun. 2014 
de uma rede urbana complexa ${ }^{1}$ e um processo de metropolização regional que é intensificado no último quartel do século XX. Tal processo de metropolização regional destaca-se por definir o peso do fenômeno urbano na nova configuração territorial da região, mas, ao contrário do que se possa imaginar, não é a homogeneização desse fenômeno o principal elemento da particularidade do espaço regional, mas sim a coexistência de formas e conteúdos urbanos diversos, a exemplo do que se verifica na escala metropolitana, que, nesse caso, são verdadeiras expressões de particularidades constatadas no plano sub-regional. É dessa forma que se configura um conjunto de centros metropolitanos na Amazônia, dentre os quais se destacam Belém (PA), Manaus (AM) e São Luís (MA), que são produto, condição e meio desse movimento de diferenciação no interior da região, e cuja dinâmica e perfil buscaremos tratar nesta análise.

\section{UMA AMAZÔNIA METROPOLITANA}

Identificada historicamente a partir de suas características biogeográficas, a região amazônica passa, especialmente a partir da segunda metade do século $\mathrm{XX}$, por uma significativa alteração de sua paisagem natural de floresta tropical, que deixa de ser a única marca referencial de sua configuração territorial. Essa alteração, proveniente do processo de produção do espaço regional em um determinado contexto histórico, coloca as cidades e o urbano entre as principais referências geográficas no final do século XX. A imagem da floresta urbanizada mencionada por Becker (2001) é simbólica nesse sentido, não pelo domínio das cidades na extensão territorial, mas pelo modo de vida e dinâmica socioespacial que marcam o ritmo da região.

Acompanhando as tendências de urbanização do território brasileiro, a Amazônia já apresentava cerca de $70 \%$ de sua população vivendo em áreas urbanas no início do século XXI, em contraste com apenas 30\% no início dos

\footnotetext{
Segundo Corrêa (1987), a rede urbana amazônica, até a década de 1960, caracterizava-se por um ordenamento territorial pouco complexo: nível simplificado de articulação entre os centros urbanos, interações espaciais em nível regional e a existência de padrões espaciais simples. $\mathrm{O}$ autor ressalta que, a partir desse período, as modificações que passaram a marcar o perfil da rede urbana foram a continuidade da criação de novos núcleos urbanos, a complexidade funcional desses mesmos centros e dos já existentes e a mais intensa articulação entre eles e para com as regiões. Tais mudanças contribuem para o desenvolvimento de um padrão de rede urbana complexo, em detrimento das formas espaciais mais simples. Nesse caso, a urbanização tem como elemento-chave a estratégia de ocupação promovida pelo Estado, com destaque para as políticas de desenvolvimento e as transformações no sistema viário que criaram novas hierarquias urbanas.
} 
anos 1950, segundo o Instituto Brasileiro de Geografia e Estatística (IBGE). Mais que a expressão estatística dessa alteração na composição demográfica da população e do povoamento regional, os dados revelam uma tendência à formação de aglomerações urbanas como as principais bases de organização do território e dos modos de vida no cenário regional; daí se falar, além da fronteira econômica que se constituiu, de uma fronteira urbana (BECKER, 1990 e 2001), marcada pela difusão do fenômeno urbano tomado no sentido dos conteúdos sociais que dinamizam as novas formas espaciais na Amazônia. Isso ocorre a partir da necessidade de estruturação de uma nova configuração da rede urbana ${ }^{2}$ regional, por meio da qual se coloca em prática o projeto de ocupação territorial.

Para Machado (1999), essa evolução recente da urbanização demonstra a configuração de "condensações" urbanas. Segundo a autora, trata-se do adensamento do número de cidades em determinadas regiões relacionado a um sistema de povoamento. Nesse caso, é necessário considerar que, para o estudo dos processos de urbanização, a presença desses adensamentos é tão importante quanto o aumento do tamanho e número de cidades ou as mudanças na estrutura hierárquica delas.

Convém salientar também que, para além do adensamento urbano, no período mais recente, uma nova forma espacial surge na dinâmica da urbanização regional, que é a emergência das aglomerações metropolitanas em consonância com o movimento mais geral de metropolização do espaço brasileiro na segunda metade do século XX. Tal processo pode ser mais bem visualizado na região amazônica através do reconhecimento de dinâmicas sub-regionais particularizadas.

Tais particularidades ajudam a compreender no conjunto deste trabalho o processo de metropolização em curso, considerando elementos tais como: a relação das formações socioespaciais metropolitanas e seu entorno sub-regional, especialmente nas suas circunscrições estaduais; o sentido da aglomeração em face do sistema de circulação regional; as conexões globais da dinâmica metropolitana; as formas de institucionalização das distintas regiões metropolitanas e as respostas oficiais do ponto de vista das políticas de planejamento e gestão a essas novas realidades espaciais.

\footnotetext{
$\mathrm{Na}$ verdade se trata da implantação de um conjunto de redes de integração espacial do território, dentre as quais a autora destaca, em conjunto com a rede urbana: a rede rodoviária, para garantir a circulação no território; a rede de telecomunicações, de forma a garantir os fluxos informacionais; e a rede hidroelétrica, que garante o suporte de energia.
}

Novos Cadernos NAEA •v. 17 n. 1 • p. 177-202 • jun. 2014 


\section{METRÓPOLES E DINÂMICAS SUB-REGIONAIS: A IMPORTÂNCIA DA CIDADE CAPITAL E AS NOVAS REGIONALIZAÇÕES NA FRONTEIRA}

Considera-se, primeiramente, a relação que esses espaços metropolitanos estabelecem com a região, especialmente em virtude de as três metrópoles analisadas - Belém, Manaus e São Luís - se apresentarem com a função de capitais de seus respectivos estados: Pará, Amazonas e Maranhão.

Segundo Machado (1999), o fato constitutivo principal dessa dinâmica da importância das cidades capitais de estados na Amazônia foi a política de incentivo à urbanização, induzida pelo Estado a partir da segunda metade do século XX, a qual partia da concepção de cidade como elemento da infraestrutura e base logística ao incremento da produção econômica regional:

O efeito dessas políticas foi a ampliação extensiva da rede urbana e o reforço à sua diferenciação hierárquica, com a permanência da primazia das capitais. Com isso, os limites políticos dos estados que formam a Amazônia "oficial" interferem na estrutura urbana e na delimitação dos subsistemas urbanos: em cada estado, a rede urbana apresenta a tendência de se organizar em função da capital (MACHADO, 1999, p. 21).

Nesse caso, é necessário atentar ainda para o movimento de formação urbana na Amazônia que, segundo Castro (2008), afirma-se em dois períodos, correspondentes também a dois padrões espaciais, no sentido de regularidades da ocupação urbana; ambos definidos a partir da ação do Estado e do mercado:

O primeiro padrão de ocupação e povoamento foi o período da intensificação da exploração da borracha - modelo de expansão urbana que se dava através dos rios com ocupação de seus vales - com base em um sistema de aviamento que se constituiu como rede de produção e fornecimento de bens e serviços nos seringais localizados no interior da Amazônia. O segundo padrão de ocupação e povoamento ocorreu a partir de 1966, intensificando-se nos anos 1970 e associado a estruturas urbanas - existentes e planejadas - para onde se dirigem os investimentos públicos, se fortaleciam instituições e se concentrava a demanda de trabalho por parte de migrantes que chegavam em fluxos intensos e crescentes (CASTRO, 2008, p. 25-26).

De fato, embora considerando a importância histórica e geográfica da formação de uma rede proto-urbana ${ }^{3}$ na Amazônia desde o período colonial,

\footnotetext{
Para Machado (1999), ainda que a exploração da borracha tenha provocado aumento dos fluxos imigratórios do Nordeste e Sudeste do País para a Amazônia, criando uma rede de povoados, vilas e pequenas cidades conectadas pelas vias fluviais, a falta de equipamentos, mesmo nas maiores aglomerações, não estimulava o desenvolvimento do modo de vida urbano. O ritmo de vida nas aglomerações menores era lento e intermitente, acompanhando a sazonalidade da coleta da borracha. Assim, essas
} 
há de se atentar que é somente a partir das políticas de integração que essa rede passa verdadeiramente a assumir uma forma complexa. Nesse caso, sustenta-se que a malha urbana mais recente na Amazônia foi dinamizada por um processo único, derivado do projeto de integração da região ao território nacional. E isso se torna especialmente verdadeiro para compreender as formações metropolitanas regionais, constituídas todas pós-1960, em total consonância com as políticas de desenvolvimento regional do período.

Entretanto, embora derivadas de um processo único, o projeto de integração regional, nota-se também que as relações estabelecidas entre as cidades de perfil metropolitano e seus estados não são estritamente homogêneas, ou seja, as metrópoles na Amazônia também têm em sua constituição a influência de particularidades sub-regionais, o que é percebido quando se considera as diferenças existentes na relação estabelecida entre as metrópoles e suas hinterlândias imediatas.

Para compreender essas particularidades é necessário considerar, de um lado, a história de formação da Amazônia desde o seu período de colonização, que resultou em formas de apropriação diversa do território até os anos de 1950, especialmente as diferenças de formação no caso das cidades analisadas (Belém, Manaus e São Luís). O fato de terem histórias de constituição distintas torna-se relevante para compreender o grau de importância que cada uma dessas aglomerações apresenta para a região em períodos históricos diferenciados.

Por outro lado, embora a história regional pré-1960 seja uma explicação válida para identificar a gênese dessas aglomerações, há de se considerar que é a chegada das estratégias de integração, povoamento e desenvolvimento, na segunda metade do século XX, que provocou, justificou e intensificou o padrão de ocupação urbana existente na atualidade, expresso inclusive no crescimento populacional das mesmas (Tabela 1$)^{4}$.

características, mais a dificuldade de comunicação e a quase ausência de diferenciação funcional entre as aglomerações, indicam que não existiam as condições para o desenvolvimento da rede urbana. Contudo, o povoamento associado à exploração da borracha nos vales impulsionou uma proto-urbanização da região. A forma da rede proto-urbana estava relacionada à áréa de ocorrência da borracha, as mais produtivas localizadas nas florestas de várzea. É a associação entre essa restrição ecológica e o domínio da circulação fluvial que explica a forma dendrítica da rede proto-urbana (MACHADO, 1999).

4 Os percentuais das populações das aglomerações foram calculados inicialmente (ano de 1950) considerando o contingente do núcleo principal e acrescidas das populações dos demais municípios metropolitanos a partir das décadas subsequentes em que foram constituídas as respectivas regiões metropolitanas, a saber: Região Metropolitana de Belém, instituída na década de 1970 e ampliada nas décadas de 1990 e 2010; Região Metropolitana de Manaus, reconhecida na década de 2000; Região Metropolitana de São Luís, instituída na década de 2000 e ampliada na década de 2010.

Novos Cadernos NAEA • v. 17 n. 1 • p. 177-202 • jun. 2014 
Tabela 1 - Belém, Manaus e São Luís: participação da população metropolitana em relação aos respectivos estados da federação.

\begin{tabular}{c|c|c|c}
\hline Ano & $\begin{array}{c}\text { Pop. Belém/PA } \\
\mathbf{( \% )}\end{array}$ & $\begin{array}{c}\text { Pop. Manaus/AM } \\
\mathbf{( \% )}\end{array}$ & $\begin{array}{c}\text { Pop. São Luís/MA } \\
\mathbf{( \% )}\end{array}$ \\
\hline 1950 & 22,70 & 27,16 & 17,10 \\
\hline 1960 & 25,93 & 24,31 & 14,85 \\
\hline 1970 & 30,00 & 32,70 & 17,15 \\
\hline 1980 & 28,50 & 44,34 & 18,50 \\
\hline 1991 & 25,10 & 48,05 & 14,30 \\
\hline 2000 & $29,00^{*}$ & 49,90 & 18,90 \\
\hline 2010 & $27,80^{*}$ & $61,10^{*}$ & $20,10^{*}$ \\
\hline 2013 & $28,00^{*}$ & 61,10 & $21,80^{*}$ \\
\hline
\end{tabular}

Fonte: IBGE. (Censos Demográficos, 1950, 1960, 1970, 1980, 1991, 2000, 2010 e estimativas 2013).

* Considera os municípios que passaram a compor a Região Metropolitana.

É possível ainda reconhecer cartograficamente essas aglomerações de perfil metropolitano através da Figura 1, ao menos em seu aspecto populacional, como as três maiores aglomerações urbanas na Amazônia Legal ${ }^{5}$.

A forma como foram estabelecidas as políticas de integração é um componente elucidativo dessas diferenciações sub-regionais, posto que há uma imbricação entre a formação das metrópoles e o seu entorno sub-regional, quando consideradas em perspectiva.

5 Considerando os números absolutos da população das três metrópoles analisadas: Região Metropolitana de Belém: 2.242.636 milhões de habitantes; Região Metropolitana de Manaus: 2.316.171 milhões de habitantes; Região Metropolitana de São Luís: 1.479 .585 milhões de habitantes (IBGE - Censo 2010 e estimativas 2013). 
Figura 1 - População da Amazônia Legal (2010).
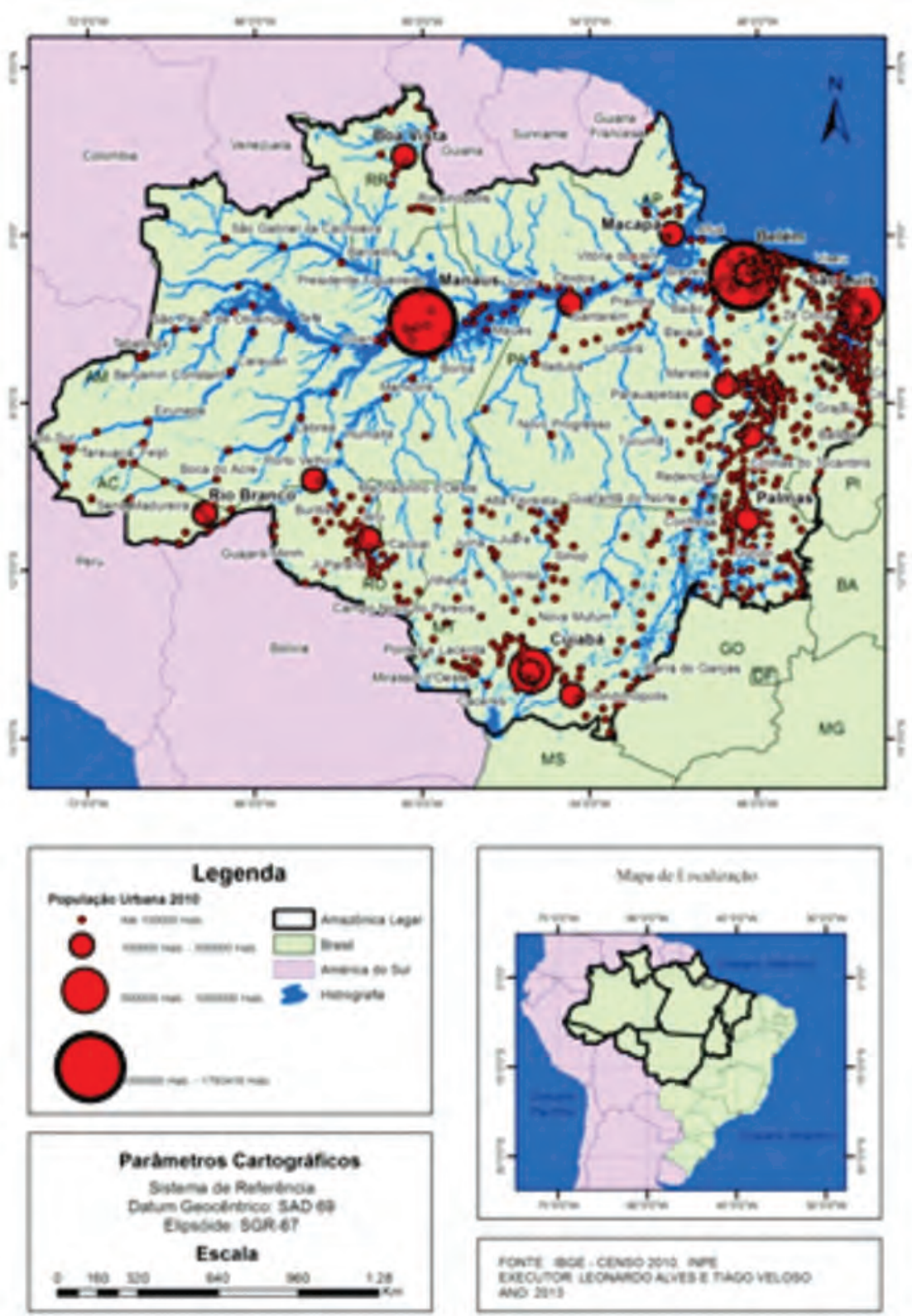

gonit ase cevesona nos

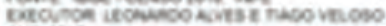
aro ans

Sendo assim, conforme já salientado, interessante é atentar que as políticas de desenvolvimento estabelecidas pós-1960 não tiveram repercussão homogênea na região. Assim, se mesmo antes desse período já não se podia afirmar a existência de uma homogeneidade regional amazônica, especialmente em seu 
conteúdo urbano, as diferentes formas de integração dessa região também foram responsáveis por criar - ou intensificar - uma diferenciação intrarregional ainda mais aguda, sendo que em boa parte as grandes cidades como Belém, Manaus e São Luís foram elementos representativos dessas diferenciações sub-regionais.

Compreende-se, portanto, que a formação da rede urbana e dos centros metropolitanos na Amazônia obedece ao mesmo tempo e de forma contraditória a imperativos e comandos externos, historicamente definidores dos processos socioespaciais regionais, e também a dinâmicas internas, que influenciam as formações socioespaciais herdadas, como destaca Ribeiro (2001) acerca das redes urbanas:

[...] a rede urbana é tanto um reflexo - a partir das cristalizações oriundas do passado, como da escolha que o capitalismo faz de determinados lugares e regiões, atribuindo às cidades, uma posição na hierarquia urbana e uma especialização funcional - como também condição, pois através dela se viabiliza a (re)produção e (re)apropriação dos diversos excedentes em diferentes áreas, a circulação do valor e o consumo de bens e serviços. A rede urbana torna-se, em realidade, complexa, pois cada centro desempenha múltiplos papéis, vinculando-se, de modo diferenciado e simultaneamente, a múltiplas redes (RIBEIRO, 2001, p. 370).

Considerando ainda um segundo aspecto, também é importante notar a relação que estes centros metropolitanos apresentam com as dinâmicas macrorregionais ${ }^{6}$, especialmente tomando como referência as tendências de reestruturação do espaço amazônico apontadas por Becker (2001), representadas na Figura 2.

Comparando-se a Figura 1 (população da Amazônia Legal), com a regionalização proposta por Becker (2001), representada na Figura 2, percebese então que estes centros metropolitanos encontram-se justamente na área de

\footnotetext{
Aqui, consideramos teoricamente a proposição de Becker (2001), para quem a realização de grandes planos de desenvolvimento regional possibilitou a dinamização de uma economia de fronteira e também a dispersão de polos de crescimento econômico em vários pontos do território. Para a mesma autora, a Amazônia hoje pode ser reconhecida diferencialmente em três porções: a) a Amazônia oriental e meridional, correspondente ao arco povoado a leste e sul da floresta, respectivamente, as áreas desmatadas do sudeste do Pará e da agroindústria do cerrado mato-grossense, com expansão até os estados de Tocantins e Rondônia, e cujos limites mais avançados seriam Açailândia (MA) e Cacoal (RO); b) a Amazônia central, estendendose do nordeste do Pará à rodovia Porto Velho-Manaus-Venezuela, passível de expansão da agricultura capitalizada, como pode ser o caso da soja na Cuiabá-Santarém, no vale do Madeira, no rio Juma, com grande proporção de terras indígenas e unidades de conservação, o que the atribui grande vulnerabilidade; c) a A Amazônia ocidental, unidade ainda marcada pelo ritmo da natureza, com grande potencialidade em águas, florestas, recursos minerais, assim como a presença da concentração econômica em Manaus, o peso do narcotráfico e de agentes externos de um lado, e de índios e militares de outro, além da vulnerabilidade da fronteira política e da relativa ausência de unidades de conservação e de terras indígenas na sua parte central (BECKER, 2001).
} 
influência de cada uma das sub-regiões destacadas na regionalização proposta, o que revela uma particularidade da metropolização regional, ou seja, a existência de um elo entre as dinâmicas sub-regionais e as formações de centros metropolitanos.

No caso da porção ocidental, Manaus é a principal referência metropolitana nessa sub-região. A aglomeração manauara representa cerca de 60\% do contingente demográfico do estado do Amazonas, o que obviamente repercute em um enorme peso relativo para o Estado e demonstra forte tendência à concentração demográfica, econômica e infraestrutural na metrópole.

Figura 2 - Amazônia Legal: regionalização e macrozoneamento (2001).
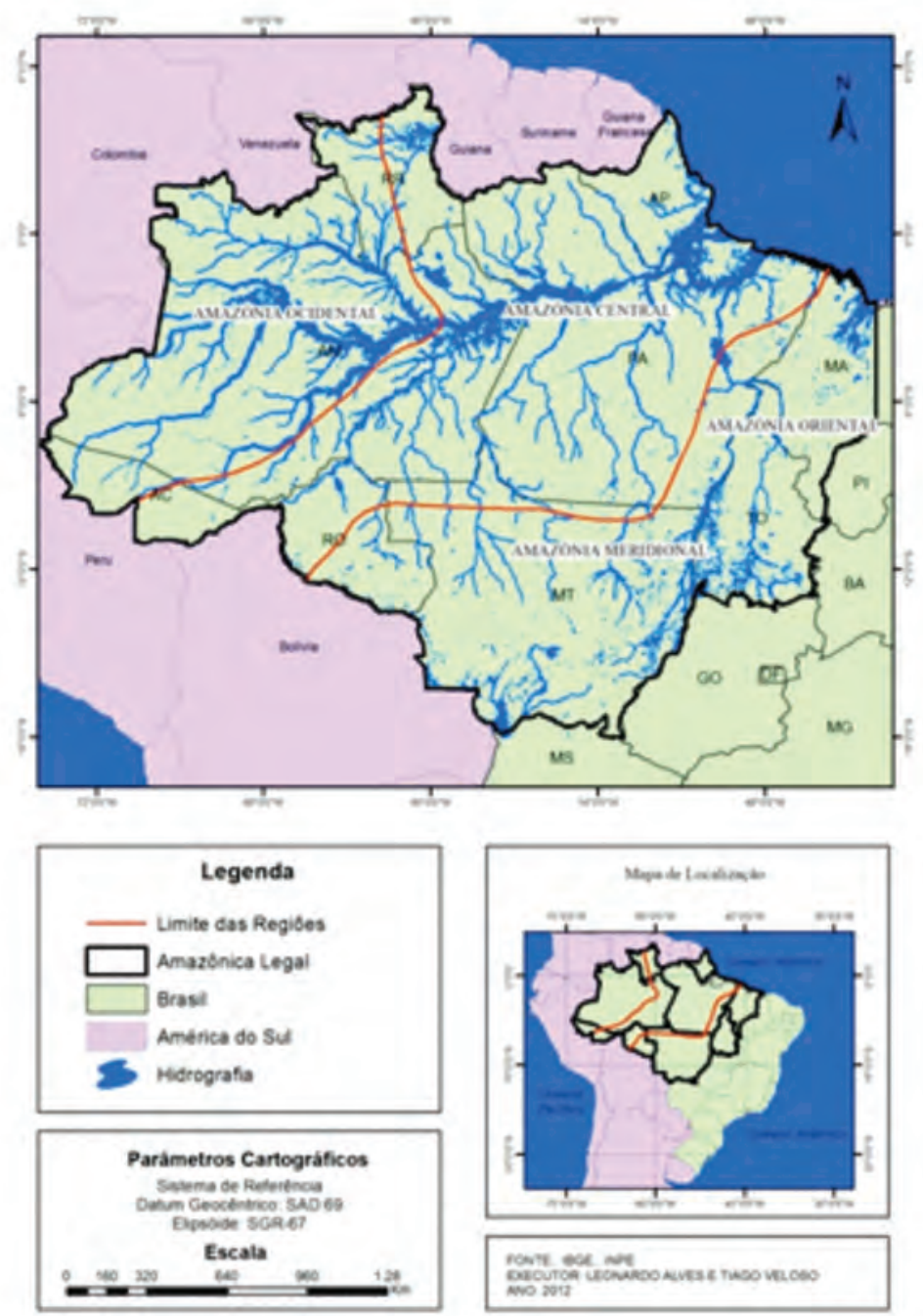

Fonte: Becker (2001).

Novos Cadernos NAEA • v. 17 n. $1 \bullet$ p. 177-202 • jun. 2014 
A principal explicação para esse fenômeno de concentração em Manaus é a existência de um complexo e dinâmico polo industrial ${ }^{7}$ na cidade, que atrai a maior parte dos fluxos econômicos e populacionais na sub-região. A estratégia de ocupação e integração dessa porção da Amazônia, através da implantação, no meio da floresta, de um polo industrial é, sem dúvida, o elemento que destaca o impacto da cidade de Manaus no contexto do estado do Amazonas e, por conseguinte, em face do entorno sub-regional.

Se a abertura de estradas de certo modo provocou pouco impacto na espacialidade da cidade de Manaus, porque a construção foi um processo lento e as dificuldades de manutenção praticamente tornaram essas vias intransitáveis nos anos 1970 e 1980, a criação da Zona Franca de Manaus e a implantação do Distrito Industrial, em 1967, tiveram efetivamente impacto na paisagem urbana de Manaus (OLIVEIRA, 2008, p. 73).

A concentração em aspectos econômicos, demográficos e de capacidade produtiva da metrópole em relação ao seu estado e ao seu entorno sub-regional também causa repercussões na produção do espaço de forma diferenciada na dinâmica de fronteira econômica, que é característica das políticas de integração e desenvolvimento na maior parte da região. Assim, um dos impactos, ainda que indireto, da existência do polo industrial de Manaus é a configuração de uma lógica que é ainda marcada pelo ritmo da natureza, com potencialidade em aliar a existência de recursos naturais (águas, florestas, minerais etc.) com uma atividade econômica de grande impacto, sem causar, necessariamente, o perfil de devastação característico da Amazônia centro-oriental, por exemplo.

Concretamente, estudos recentes ${ }^{8}$ revelam que a existência de um polo industrial dinâmico em Manaus contribuiu significativamente para a redução das pressões sobre a exploração dos recursos da floresta, o que é considerado enquanto uma alteração positiva no espaço regional. Nesse caso tem-se que considerar que

\footnotetext{
${ }^{8}$ A Zona Franca de Manaus tornou-se um polo de isenção fiscal no centro da Amazônia pelo Decreto-Lei 288, de 1967. Inicialmente sua área estava restrita à cidade de Manaus, tendo sido continuamente ampliada para outros espaços, compreendendo os estados do Amapá, Amazonas, Rondônia, Roraima e Acre, e correspondendo a aproximadamente 25\% do território nacional. A partir de 1967, além da área de livre comércio, foi instalado o distrito industrial, baseado espacialmente na montagem de componentes da indústria eletroeletrônica. 8 Estudo sobre o impacto da indústria sobre a floresta amazônica (RIVAS; MOTA; MACHADO 2009) afirma que a existência do Polo Industrial de Manaus (PIM) contribuiu para reduzir em pelo menos $70 \%$ o desmatamento no estado do Amazonas no período de 2000 a 2006. Estima ainda que o valor das emissões de carbono evitadas no período analisado chega a US\$ 10 bilhões no período. Se considerados os serviços ambientais proporcionados pela preservação, o valor estimado é da ordem de US\$ 158 bilhões também no período. O estudo, que comprova a influência do PIM na preservação da floresta amazônica, foi feito por pesquisadores das universidades federais do Amazonas e do Pará, do Projeto Inteligência Socioambiental Estratégica da Indústria do Petróleo na Amazônia (PIATAM) e do Instituto de Pesquisa Econômica Aplicada (IPEA).
} 
a causa fundamental deste fenômeno reside no fato de o polo industrial não necessitar de matéria-prima vinculada ao meio natural circundante, pois se trata de um modelo industrial importado, sendo, portanto, pouco provido de conexões que demandem a necessidade do meio natural, os recursos da floresta.

Assim, em grande medida, a Amazônia ocidental é polarizada quase que integralmente pela metrópole manauara, visto que essa porção, conforme destacada por Becker (2001), responde por boa parte de áreas ainda marcadas pelo ritmo da natureza, e com possibilidades de uso sustentável. Essa dinâmica não pode ser deslocada da influência mitigadora que o polo industrial de Manaus provocou no interior da sub-região. Ao ser fonte de fluxos econômicos e migratórios para a indústria nas décadas de 1980 em diante, acabou por se tornar em válvula de escape da pressão por recursos naturais da região, colaborando, assim, para a preservação maior dessa porção do território.

Todavia, não se pode assegurar de forma categórica que não houve repercussões significativas com a implantação do empreendimento. Indubitavelmente, os maiores impactos do polo industrial foram, certamente, no espaço intraurbano de Manaus. A pressão demográfica resultante da instalação deste, a concepção de cidade pensada como polo econômico e as estratégias governamentais de planejamento e gestão da cidade, acabaram por conferir a expressão de um espaço urbano com sérios problemas do ponto de vista urbanístico e socioespacial.

Nesse caso, pode-se dizer que a Amazônia ocidental é a que mais apresenta um processo de urbanização concentrado, reafirmando o papel macrocefálico de sua metrópole - Manaus -, que a despeito da existência de uma região metropolitana institucionalizada incluindo vários municípios, parece expressar uma forma metropolitana definida por uma malha urbana de recorte municipal, quase que exclusivamente ao município de Manaus, ainda que aponte para os próximos anos uma expansão, em razão da inauguração da ponte sobre o rio Negro, que articula Manaus a alguns municípios vizinhos.

Por outro lado, as repercussões das políticas de integração e desenvolvimento em outras porções da região foram bastante diferenciadas. Neste caso, toma-se como primeiro exemplo a porção centro-oriental, definida por Becker (2001), na qual Belém representa, em termos demográficos, cerca de $30 \%$ da população do estado do Pará.

Diferentemente da atração polarizadora exercida por Manaus na Amazônia ocidental, Belém, enquanto metrópole regional, vem paulatinamente perdendo a característica de referência de principal aglomeração urbana da Amazônia, embora, de forma alguma, perca a condição de importante metrópole.

Novos Cadernos NAEA • v. 17 n. 1 • p. 177-202 • jun. 2014 
Essa cidade, que em décadas anteriores tinha uma participação econômica e populacional de destaque no contexto regional, começa a ter sua importância alterada em face dos novos espaços de incremento econômico das décadas mais recentes; fato este que confirma uma nova dinâmica da economia política da urbanização da sub-região na qual se insere, refletida na participação de Belém em termos populacionais quando comparada ao conjunto do estado.

Essa perda relativa se deve, entre outros fatores, à existência também no território paraense de importantes cidades médias como Santarém (oeste paraense) e Marabá (sudeste paraense), e mesmo pequenas cidades que têm sua vida urbana dinamizada pela chegada de grandes projetos; fatos estes que causam uma relativa perda de importância econômica da metrópole em relação ao seu contexto sub-regional.

Belém não sofreu o estímulo de crescimento a partir do setor industrial de montagem, a exemplo do que se verificou em Manaus. Seu perfil é de uma cidade situada entre as que apresentam uma natureza metropolitana, com destaque para as atividades comerciais e de serviços. As indústrias nela instaladas - com um peso relativamente pequeno se comparado a Manaus - voltaram-se para o beneficiamento de matérias-primas da própria região e, portanto, com um impacto relativamente maior em relação à floresta.

A reestruturação da rede urbana, já mencionada, e os novos conteúdos e importância atribuídos às cidades fora do aglomerado metropolitano tendem a confirmar cada vez mais a dinâmica de uma nova estrutura produtiva e do mercado de trabalho na Amazônia centro-oriental. Isso implica, necessariamente, em rupturas de antigos padrões de organização espacial e por provocar um processo de dispersão populacional, de investimentos econômicos e de ações governamentais, associados também direta ou indiretamente a novas vias de circulação mais presentes nessa porção territorial da Amazônia.

O mercado de trabalho da Amazônia oriental tende a confirmar desde a década de 1990 o processo de reestruturação em curso, posto que os setores mais dinâmicos nos últimos anos têm sido a mineração, a indústria madeireira, a siderurgia e a construção civil (CASTRO, 1994) e, por isso mesmo, as cidades ligadas direta ou indiretamente a essas atividades experimentaram um novo dinamismo, alterando a rede urbana regional, seja através da multiplicação de novos núcleos populacionais, planejados ou não, seja pela redefinição de antigos núcleos urbanos que se alçam à categoria de verdadeiros centros regionais, ou mesmo por um novo padrão de urbanização concentrada.

Entretanto, conforme já mencionamos, a expansão da fronteira econômica no interior da região não se dá de maneira igual quando consideramos 
a especificidade das sub-regiões. Diferentemente da Amazônia ocidental, a Amazônia centro-oriental cresce mais que sua metrópole (Belém), devido ao dinamismo econômico imprimido a outras frações do espaço regional nos últimos anos, onde são implantados projetos, em especial os grandes empreendimentos, que necessitam de espaços urbanos relativamente bem estruturados para o seu funcionamento, mas que não se limitam a eles, implicando em redefinições espaciais que alcançam um raio de influência relativamente significativo e que repercutem no grau de urbanização do território.

Nesse sentido, os investimentos econômicos na área de influência da metrópole belenense deram-se de forma menos concentrada que em outros espaços do conjunto regional. A interpretação desse processo, nos termos e parâmetros colocados acima, costuma ser associada ao movimento que tem marcado a dinâmica urbana brasileira. Conforme mostra Santos (1993), as grandes metrópoles brasileiras já apresentam taxas de crescimento econômico menores do que suas respectivas regiões, e também menor do que a brasileira como um todo. Isto é traduzido pelo mesmo autor como um fenômeno de "involução metropolitana", que representa o ritmo de crescimento das áreas metropolitanas menos acelerado, quando comparado a décadas anteriores, em relação às áreas que se encontram fora da área metropolitana.

É um fenômeno que também se dá paralelo a outro, o da consolidação da metrópole informacional e não propriamente da metrópole fabril, posto que, cada vez mais, as unidades produtivas promovem uma seletividade espacial movida por fatores diversos - incentivos locais, mão de obra barata, infraestrutura, preço de terrenos mais acessíveis etc. - que tendem a preterir os limites convencionais das áreas metropolitanas, devido às desvantagens e restrições por elas apresentadas em relação a esses mesmos fatores.

Há novos recortes espaciais no interesse do capital, decorrentes de mudanças em suas estratégias. Dentre estas, a principal é o aumento significativo da fluidez do território, devido ao progresso nos transportes, nas comunicações e na produção e uso das informações, que também se reproduz na realidade amazônica.

Todavia, é importante considerar que não é em qualquer ponto do sistema urbano brasileiro que esse processo se manifesta. No caso amazônico, a malha técnico-política implantada a partir da década de 1960, com a abertura de rodovias, com os incentivos fiscais e creditícios e com os grandes projetos econômicos, buscava aumentar essa fluidez do território, de modo a conectá-lo de maneira decisiva à divisão territorial do trabalho que se impunha em nível nacional e internacional. 
Mesmo considerando a pertinência dessa tendência também para o caso da Amazônia centro-oriental, há de se levar em conta, entretanto, que o processo que confere um maior dinamismo para o interior da fronteira econômica em detrimento da sua metrópole, não pressupõe desconsiderar a importância do espaço metropolitano para os processos dinamizadores da economia regional, mas de uma redefinição dessa mesma importância conforme já argumentamos em outra oportunidade (TRINDADE JR., 1998). No caso da Amazônia centrooriental, em boa parte do território paraense, trata-se de uma porção que não está sob influência unicamente da metrópole belenense, visto que, como dito anteriormente, nessa sub-região destacam-se também a proliferação de pequenas cidades e o crescimento e dinamismo de cidades de porte médio no interior da Amazônia, especialmente aquelas influenciadas pelas dinâmicas de grandes projetos.

De forma semelhante, na porção mais oriental, São Luís, que representa cerca de 20\% da população do estado do Maranhão (IBGE, 2010), também revela especificidades no seu processo de metropolização. A sub-região na qual se insere tem como grandes características de inserção na dinâmica de fronteira da Amazônia a implantação ou repercussão de grandes projetos de extração mineral como os promovidos pela então Companhia Vale do Rio Doce (hoje VALE), como o ALUMAR (Alumínios do Maranhão S. A.), durante a década de 1970, que criou a expectativa de desenvolvimento econômico do estado do Maranhão, assim como do município de São Luís, que refletiu a ideia de desenvolvimento socioeconômico da cidade em consequência da implantação dos grandes projetos.

De fato, São Luís, dentre as três metrópoles analisadas, é a que apresenta a maior taxa de crescimento demográfico dos anos 1990 em diante, chegando a condição de "cidade milionária" (SANTOS, 1993), ou seja, com um milhão de habitantes. Entretanto, assim como em outras áreas que também receberam a implantação de grandes projetos, as repercussões na dinâmica regional, embora com dinamização da economia local, trouxe profundas mudanças negativas na produção do espaço. Neste contexto, verifica-se também o processo de segregação urbana, que tem como resultado a produção de espaços periféricos no interior da metrópole, também configurando uma metropolização periférica. Processos semelhantes ocorreram também em Manaus, já a partir dos anos 1980.

Elemento importante definidor desse fenômeno é a relação da aglomeração de São Luís com a mina (VICENTINI, 2004). Mesmo estando localizada no estado do Pará, a mina de ferro de Carajás imprimiu uma dinâmica territorial importantíssima para o oeste do estado do Maranhão, por meio do escoamento do minério de ferro pela ferrovia de Carajás e pelo porto de Itaqui, no Maranhão. 
Trata-se da primeira grande ferrovia moderna na Amazônia, com $890 \mathrm{~km}$ de extensão, que atravessa parte do território da bacia amazônica, ligando a metrópole de São Luís, no litoral atlântico à serra dos Carajás no sudeste paraense (VICENTINI, 2004).

Em todo o percurso, da metrópole de São Luís à mina de Carajás, atravessando o estado do Maranhão até a reserva mineral de Carajás, no Pará, criaram-se novas condições de apropriação territorial, fazendo com que surgissem vários núcleos urbanos e povoados ao longo da ferrovia na região do Médio Vale do Pindaré, no Maranhão; e no trecho entre Marabá e Carajás, no Pará (VICENTINI, 2004, p. 193).

A dinâmica dessa porção oeste do estado acompanha, em grande parte, as políticas territoriais estabelecidas para o estado do Pará e para a parte meridional da Amazônia, responsável por uma dinâmica migratória intensa e a constituição de uma fronteira de expansão capitalista, pela estruturação de uma sub-região conflituosa e de rápidas transformações sociais e econômicas, assim como por estimular o processo de metropolização verificado hoje em São Luís; daí reconhecermos essa parte do território brasileiro como sendo integrante do complexo regional amazônico. No caso de São Luís, há um diferencial também em relação àquilo que acontece em relação a Belém, uma vez que os elementos da cidade corporativa (SANTOS, 1993) associada aos grandes empreendimentos se fazem presentes no interior da aglomeração:

A Alumar instalou junto à produção uma cidade empresarial e no interior da cidade de São Luís um condomínio para seus principais dirigentes, verdadeiro contraste com a cidade, definindo um espaço disciplinado e antagônico, com escolas e clube privado, de acesso absolutamente restrito (VICENTINI, 2004, p. 197).

Para além do grande empreendimento e do porto conectado à ferrovia, a cidade cresce incorporando à sua malha urbana municípios vizinhos que passam a formar, mesmo que às vezes de forma descontínua, uma malha urbana única.

Nesse caso, é possível inferir, a partir de um olhar mais generalizante do processo de metropolização na Amazônia, que as metrópoles em questão, Belém, Manaus e São Luís, exercem algum tipo de influência em cada uma destas três porções consideradas no corpo deste trabalho. O Quadro 1 mostra de forma sintética e esquemática alguns elementos caracterizadores dessas metrópoles e da relação com suas respectiva sub-regiões. 


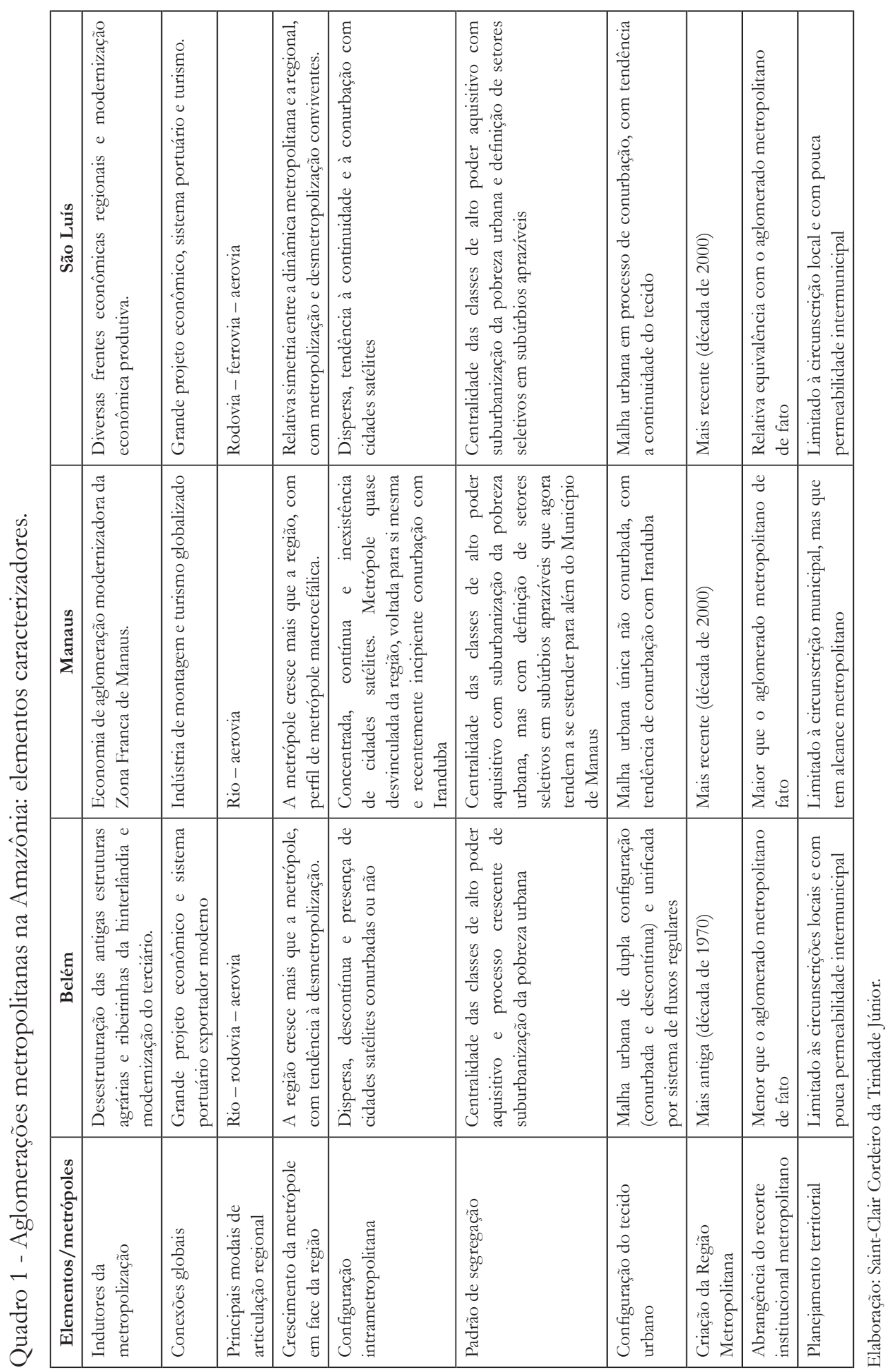


O tipo de urbanização dessas porções amazônicas aqui consideradas é diferenciado e tem reflexos significativos na composição da estrutura urbana e metropolitana representada por suas respectivas aglomerações, que apresentam tendências diversas. Belém vem perdendo relativamente importância na organização do espaço regional, em parte por conta de crescimento de cidades de porte médio com setores econômicos mais dinâmicos que a capital no interior do estado do Pará. São Luís, de outra forma, apresenta crescimento demográfico muito acima da média nas cidades capitais, consolidando seu papel de metrópole. Por outro lado, Manaus, continua sendo uma referência polarizadora não só no contexto estadual do Amazonas, mas também no entorno sub-regional, em virtude da dependência econômica e demográfica advinda do polo industrial, ainda que com forte dependência de incentivos fiscais, com prorrogação negociada das datas para o término de tais incentivos.

\section{A INSTITUCIONALIZAÇÃO METROPOLITANA E OS DESAFIOS DO PLANEJAMENTO TERRITORIAL}

Outro aspecto levado em conta na análise dessas aglomerações, para além das relações entre estas e seu entorno regional, são suas características de organização interna. Nesse caso, a principal variável analisada até o presente é o aspecto institucional desses centros metropolitanos, considerando que esse processo de metropolização do espaço não deixa de ser percebido pelos agentes políticos. A principal resposta por parte do Estado tem sido as diversas propostas de institucionalização de regiões metropolitanas para fins de execução de políticas de planejamento e administração do espaço metropolitano em escala nacional.

Essa estratégia pode ser mais bem visualizada a partir de dois momentos da vida política nacional. A primeira, na década de 1970, com a instituição de regiões metropolitanas ainda sob o regime militar ${ }^{9}$; o segundo, a partir da redemocratização dos anos 1980 e as novas demandas em torno das políticas urbanas, especialmente nas regiões metropolitanas.

A criação de áreas metropolitanas no primeiro momento, do qual a criação da Região Metropolitana de Belém é o exemplo de referência para a Amazônia, constituiu parte de uma estratégia geopolítica de integração do território nacional

\footnotetext{
9 De 1964 a 1985, o Brasil viveu um período ditatorial, governado de forma rotativa por generaispresidentes. Uma das principais características político-administrativas desse regime estava na centralização da execução das políticas urbanas na esfera federal de governo, em detrimento das esferas estaduais e municipais (locais). Essa característica influenciou de forma duradoura a constituição das políticas para as metrópoles brasileiras nesse período.
}

Novos Cadernos NAEA • v. 17 n. $1 \bullet$ p. 177-202 • jun. 2014 
e de desenvolvimento econômico. Partia-se da premissa de que o conjunto hierarquizado de cidades, funcionalmente interdependentes, representava um recurso básico para atender à realização de metas comuns e a princípios de equilíbrio do sistema (DAVIDOVICH, 2004).

Nesse caso, as principais características desse período no plano da institucionalização eram: a) o componente autoritário da intervenção, materializado na centralização de decisões na esfera federal de governo e na perda de autonomia de entes federados como estados e municípios; b) o estabelecimento de uma estrutura institucional para planejar, financiar e executar as ações de alcance metropolitano; c) a disponibilidade de recursos financeiros que permitiram a implementação de projetos metropolitanos, especialmente nas áreas de transporte coletivo e tráfego urbano.

Diferentemente desse contexto, a criação de regiões metropolitanas de Manaus e São Luís ocorre em um período distinto da criação da Região Metropolitana de Belém (RMB). Na verdade, em contraposição ao modelo de ações em nível metropolitano verificadas nas décadas de 1970 e início de 1980, especialmente a partir da Constituição de 1988, é estabelecido um novo marco normativo das ações da política urbana e metropolitana. A inauguração dessa nova fase decorreu da crise de um modelo coercitivo que não contava mais com o cenário político centralista, com os recursos solapados pela crise de financiamento do Estado e pelo concomitante desmonte da superestrutura de apoio federal ao planejamento urbano.

No aspecto normativo, o estabelecimento de regiões metropolitanas passa a ser de competência das esferas estaduais de governo, e não mais do governo federal. Isso acarreta uma descentralização das ações do governo federal, principal estimulador das políticas metropolitanas no período. Além disso, já no contexto de crise fiscal do Estado brasileiro na década de 1980, instituições como o Banco Nacional de Habitação (BNH) e o Serviço Federal de Habitação e Urbanismo (SERFHAU) vivenciaram um processo contínuo de desidratação de seus recursos econômico-financeiros, passando assim a serem secundários na execução das políticas urbanas, especialmente as políticas metropolitanas. Isso se refletiu na criação de entidades administrativas metropolitanas criadas na Amazônia nos anos 2000 (DAVIDOVICH, 2004; GOUVÊEA, 2005).

Nesse caso, um dos principais objetivos do surgimento dessas entidades (ainda que não explicitamente declarados), é a possibilidade de maior acesso aos recursos destinados a essas áreas ${ }^{10}$, o que também

10 A estratégia de criação de regiões metropolitanas como forma de inserção das cidades de referência nos circuitos de financiamentos para espaços urbanos, especialmente recursos 
envolve uma série de disputas políticas em nível local, conforme revela o Quadro 2.

Quadro 2 - Belém, Manaus e São Luís: perfil de institucionalização das regiões metropolitanas

\begin{tabular}{|c|c|c|}
\hline Instituição & Municípios & Processo de criação \\
\hline $\begin{array}{c}\text { Região } \\
\text { Metropolitana } \\
\text { de Belém } \\
\text { (RMB) }\end{array}$ & $\begin{array}{c}\text { Belém, Ananindeua, } \\
\text { Benevides, } \\
\text { Marituba, Santa } \\
\text { Bárbara do Pará, } \\
\text { Santa Izabel do } \\
\text { Pará, Castanhal. }\end{array}$ & $\begin{array}{l}\text { Criada em } 1970 \text { pelo governo federal a } \\
\text { partir da definição de realização de serviços } \\
\text { comuns, em conjunto com outras oito regiões } \\
\text { metropolitanas em território nacional. Após a } \\
\text { redemocratização obteve a formalização com } \\
\text { a Constituição do Estado do Pará em 1989, e a } \\
\text { instituição de regiões metropolitanas tornada } \\
\text { atribuição estadual. A partir de então a RMB } \\
\text { obteve seu reconhecimento em âmbito } \\
\text { estadual em } 1995 \text { com a Lei Complementar } \\
\text { no 027, sendo ampliada recentemente com } \\
\text { a inclusão de novos municípios como Santa } \\
\text { Izabel do Pará e Castanhal. }\end{array}$ \\
\hline $\begin{array}{c}\text { Região } \\
\text { Metropolitana } \\
\text { de Manaus } \\
\text { (RMM) }\end{array}$ & $\begin{array}{c}\text { Manaus, Rio Preto } \\
\text { da Eva, Presidente } \\
\text { Figueiredo, } \\
\text { Iranduba, Novo } \\
\text { Airão, Careiro da } \\
\text { Várzea, Itacoatiara, } \\
\text { Manacapuru. }\end{array}$ & $\begin{array}{l}\text { Criada pela Lei Complementar 052, de } \\
30 \text { de maio de } 2007 \text {. Trata-se de uma } \\
\text { institucionalização que apresenta contornos } \\
\text { de artificialidade, dada a necessidade de } \\
\text { acesso a recursos federais específicos para } \\
\text { áreas metropolitanas. Comparada às demais, } \\
\text { os argumentos técnicos arrolados parecem } \\
\text { mais precários, como a ausência de áreas } \\
\text { conurbadas. Em dezembro de 2007, foi } \\
\text { inserido o município de Manacapuru, por } \\
\text { meio da Lei Complementar 059. Além disso, } \\
\text { em outubro de } 2011 \text { o Tribunal de Justiça do } \\
\text { Amazonas aprovou a inserção de mais cinco } \\
\text { municípios (Careiro, Autazes, Manaquiri, } \\
\text { Silves e Itapiranga) à RMM, questão que } \\
\text { estava em processo de julgamento por ser } \\
\text { proposta do Legislativo por meio da Lei } \\
\text { Complementar 064, de abril de } 2009 \text {. }\end{array}$ \\
\hline
\end{tabular}

advindos da esfera federal da administração, tem se espalhado pela Amazônia. Atualmente as duas principais cidades médias do estado do Pará, tem proposta em discussão na Assembleia Legislativa Estadual de se constituir em regiões metropolitanas, ainda que tenham pouco ou mesmo nada de conteúdo metropolitano, segundo os critérios apresentados. A proposta de criação da Região Metropolitana de Marabá no sudeste paraense com os municípios de Marabá, São João do Araguaia, São Domingos do Araguaia, Bom Jesus do Tocantins, Nova Ipixuna e Itupiranga. A outra proposta é a criação da Região Metropolitana de Santarém, composta pelos municípios de Santarém, Belterra, e Mojuí dos Campos (município ainda não legalmente emancipado). Pode-se incluir nessa categoria também, Macapá, capital do estado do Amapá.

Novos Cadernos NAEA • v. 17 n. 1 • p. 177-202 • jun. 2014 


\begin{tabular}{|c|c|c|}
\hline $\begin{array}{c}\text { Região } \\
\text { Metropolitana } \\
\text { da Grande São } \\
\text { Luís (RMGSL) }\end{array}$ & $\begin{array}{l}\text { São Luís, Alcântara, } \\
\text { Paço do Lumiar, } \\
\text { Raposa, São José de } \\
\text { Ribamar. }\end{array}$ & $\begin{array}{l}\text { A RMGSL foi criada a partir da Lei estadual } \\
\text { № } 69 \text { de } 2003 \text {, que deu nova redação à Lei } \\
\text { de } 38 / 1998 \text {, dispondo sobre esse tema. Seria } \\
\text { um órgão formado por representantes de } \\
\text { cada governo municipal da RM e do governo } \\
\text { estadual, ficando a participação popular } \\
\text { regulamentada no regimento interno. }\end{array}$ \\
\hline
\end{tabular}

Organização: Tiago Veloso dos Santos com a colaboração de Marcos Castro de Lima.

Nesse aspecto, é necessário afirmar que as metrópoles amazônicas, apesar de seu caráter de diferenciação regional, são objeto de políticas de planejamento e gestão que, em regra, são produzidas a partir de outras realidades metropolitanas brasileiras, o que dificulta o entendimento da diferenciação regional devido ao caráter muitas vezes homogeneizador dessas políticas.

A Região Metropolitana de Belém, o fato de ter sido criada ainda nos anos 1970, com a definição de realização de serviços comuns, em conjunto com outras regiões metropolitanas do território nacional, possibilitou a adoção de políticas de planejamento metropolitano, que, nesse caso, tinham como características o componente autoritário de intervenção da esfera federal no plano local e o estabelecimento de uma estrutura institucional para planejar, financiar e executar as ações de alcance metropolitano.

Entretanto, parte dessa experiência de planejamento com base no território metropolitano foi parcialmente invertida após o período de redemocratização. A consolidação de um novo marco normativo das políticas urbanas a partir da Constituição de 1988 possibilitou um segundo momento de formalização da Região Metropolitana de Belém, mas, desta feita, veio desacompanhada de mecanismos e instrumentos de execução das diretrizes do planejamento. Para além disso, a retórica municipalista, em contraponto às tendências centralizadoras do planejamento no passado, e a problemática da diversidade administrativa - já que, no caso brasileiro em sua ampla maioria, as metrópoles são formadas por várias municipalidades -, com perfis de administração que podem ser não apenas diversos, mas também opositivos, geram dificuldades quanto à permeabilidade do planejamento e da gestão urbana entre as malhas municipais oficialmente definidas. Em período mais recente, a RMB assume novos contornos, com caráter mais disperso em relação ao passado, com a inclusão de novos municípios no recorte metropolitano ${ }^{11}$;

11 Estamos nos referindo aos municípios de Santa Izabel do Pará, incluído na Região Metropolitana de Belém em 2009, e Castanhal, incluído em 2011. Existe ainda a demanda para inclusão do município de Barcarena, que até o presente momento não foi efetivada. 
municípios estes que já fazem parte da dinâmica metropolitana, mas que até então não eram reconhecidos institucionalmente.

No caso de Manaus, as dificuldades de consolidação de um planejamento territorial devem-se, também, às características particulares de sua territorialidade metropolitana, posto que se trata de um município metropolitano, mas que constitui uma região metropolitana com vários outros municípios não necessariamente articulados, para fins de acesso a recursos destinados a essas entidades. Assim, nesse caso específico, a constituição de uma política para as metrópoles de caráter homogêneo obriga a gestão a ir à direção da fragmentação, quando no aspecto real a metrópole se apresenta muito mais como uma unidade em torno do município principal.

Além disso, as disputas entre as próprias municipalidades para fazerem parte da região metropolitana, como no caso da querela judicial envolvendo a inserção de mais cinco municípios (Careiro, Autazes, Manaquiri, Silves e Itapiranga) na RMM, através do Tribunal de Justiça do Amazonas, demonstram a dificuldade de execução de políticas metropolitanas com base em princípios de gestão compartilhada, dada a diversidade de interesses em questão e as necessidades de recursos, especialmente dos municípios menores.

No caso de São Luís, a institucionalização metropolitana também parece pouco clara. A chamada Região Metropolitana da Grande São Luís (RMGSL), conforme foi denominada, foi criada a partir de Lei estadual de 2003, que reconhece um dispositivo legal datado de 1998, dispondo sobre o tema. A dificuldade está na formação de um órgão constituído por representantes de cada governo municipal da Região Metropolitana e também do governo estadual, ficando a participação popular regulamentada no regimento interno. A lei se refere a essa entidade pela sigla Conselho de Administração e Desenvolvimento da Grande São Luís (COADEGS). Nesse caso, a "efetivação da RMGSL", estaria somente dada com a formação do arranjo institucional gestor da região, previsto em lei.

Além disso, o fato de o estado possuir outra região metropolitana além da RMGSL, a Região Metropolitana do Sudoeste Maranhense, formada por oito municípios da Mesorregião Oeste Maranhense (Lei Complementar Estadual 89/2005), coloca novamente a questão das institucionalizações metropolitanas em áreas que não necessariamente são metrópoles, mas sim, formas outras de aglomerações urbanas ou regionais, sem escala ou conteúdo metropolitano.

Portanto, percebe-se que a política exclusivamente homogênea para as metrópoles cria distorções institucionais e acaba tendo repercussões negativas no plano territorial, agravando os problemas de fragmentação da política que, de outra forma, visam a minimizar. Por outro lado, a falta de um conceito mais claro 
do ponto de vista técnico do significado da metrópole em termos socioespaciais provoca uma recorrência exagerada à institucionalização de aglomerados urbanos de naturezas diversas, como acontece no caso amazônico.

\section{CONSIDERAÇÕES FINAIS}

Apresentamos a ideia central de que no processo de urbanização da Amazônia, particular importância assume a urbanização concentrada, definindo, igualmente, o processo de metropolização das aglomerações de Belém, Manaus e São Luís. Nesse sentido, procurou-se mostrar que, ao contrário do que se poderia pensar a priori, a urbanização concentrada não perde importância no momento atual, em face da expansão da fronteira econômica verificada no interior da região que possibilita o aparecimento e o crescimento de novos centros urbanos e econômicos, ainda que esse processo se manifeste de forma diferenciada, de acordo com a sub-região em que se inserem as metrópoles.

Utilizou-se a regionalização proposta por Becker (2001) para situar as particularidades e a diversidade da dinâmica metropolitana na Amazônia. Para essa autora três sub-regiões mais amplas podem ser reconhecidas no espaço regional, a saber: a Amazônia ocidental, a Amazônia central e a Amazônia oriental. Para efeitos do presente estudo, a nomeação da autora foi considerada, a exceção da Amazônia central. A partir da regionalização proposta pela autora, traça-se um paralelo com as três aglomerações metropolitanas da região, nucleadas pelas cidades de Belém, Manaus e São Luís, que de forma diferenciada encontram-se territorialmente ligadas a cada uma daquelas sub-regiões.

Dentre as características das sub-regiões, a Amazônia ocidental é que mais apresenta um processo de urbanização concentrado, reafirmando o papel macrocefálico de sua metrópole, a cidade de Manaus, que a despeito da existência de uma região metropolitana institucionalizada incluindo vários municípios, parece expressar uma forma metropolitana definida notadamente por uma malha urbana relativamente circunscrita ao município de Manaus, ainda que aponte para os próximos anos uma expansão para além deste em razão da inauguração da ponte sobre o rio Negro, que articula Manaus a alguns municípios vizinhos. Aqui a RMM se confunde com Manaus. Trata-se da identidade de Manaus forjando uma identidade metropolitana que lhe é singular, para municípios que não possuem essa identidade metropolitana. O papel do discurso, em relação ao território e seus possíveis recursos, nesse sentido, é muito forte. 
Processo diferenciado se apresenta para o caso belenense, que definiu um processo de metropolização marcado inicialmente pela conurbação de Belém com alguns municípios vizinhos e que hoje tende a configurar uma malha urbana mista, ora conurbada, ora descontínua, inclusos nesse caso, municípios que oficialmente não integram a região metropolitana oficial, como é o caso de Barcarena, onde se situa o importante complexo produtor de alumínio e alumina e o novo porto de Belém, especializado na exportação de minério semi-industrializado.

Belém vivencia ainda um processo diferenciado em razão do maior dinamismo de sua sub-região, pelo surgimento de grandes projetos e de polos de crescimento induzidos por políticas de desenvolvimento em espaços situados fora da órbita metropolitana, mas cujas consequências demográficas, migratórias e de pouco acesso a postos de trabalho repercutiram na expansão da malha metropolitana que cresceu bastante nas últimas décadas.

O caso de São Luís parece apresentar dois processos que corroboram para a sua dinâmica metropolitana. Um que se manifesta do interior de sua sub-região em direção à metrópole, em razão de sua articulação com o grande projeto Carajás e a sua conexão através da ferrovia, que estabelece um interessante binômio mina-metrópole (VICENTINI, 2004) e outro que se manifesta internamente à metrópole, marcado pela instalação de complexo industrial de alumina associado à estruturação de um porto exportador, cujo destaque é dado ao minério de ferro.

Trata-se, inegavelmente, de três realidades distintas que parecem corroborar para a compreensão das particularidades sub-regionais no espaço amazônico e que se expressam por meio de três formas metropolitanas que são, ao mesmo tempo, produto, condição e meio da dinâmica que se verifica em escala sub-regional.

Por outro lado, no quesito da criação de políticas de planejamento e gestão do espaço metropolitano a principal iniciativa proposta de desenvolvimento dessas políticas foi a criação de áreas metropolitanas como territórios privilegiados de controle do espaço. Ainda assim, aquelas também foram bastante diferentes do ponto de vista temporal e histórico. Em um primeiro momento, na década de 1970, a Região Metropolitana de Belém é o exemplo de referência, constituindo componente de uma estratégia geopolítica de integração do território nacional e de desenvolvimento econômico. Diferentemente desse contexto, a criação de regiões metropolitanas de Manaus e São Luís, ocorre em um período distinto, já no final da década de 1990 e início dos anos 2000, ocasionando perspectivas diferentes de planejamento e gestão mais ligadas a questões estaduais e não necessariamente vinculadas a um projeto nacional.

Se a homogeneidade regional amazônica já vinha sendo contestada do ponto de vista de sua biodiversidade e da sua sociodiversidade, os exemplos aqui tratados reforçam a necessidade de estender o atributo da diversidade verificada na Amazônia ao seu processo de urbanização e, dentro deste, na sua 
expressão metropolitana. Essa urbanodiversidade que aí se expressa, mais que sugerir tipos diferenciados de formas e conteúdos urbanos, possibilitam pensar em políticas urbanas também diferenciadas e mais adequadas aos processos que se manifestam em nível sub-regional, contrapondo-se, assim, àquelas formas de intervenção nos territórios e nas cidades que tendem a padronizar o ordenamento territorial, secundarizando particularidades sub-regionais e singularidades locais, conforme se pode constatar com a institucionalização das regiões metropolitanas na Amazônia, nem sempre condizentes com os processos socioespaciais que se expressam nesse nível de aglomeração urbana.

\section{REFERÊNCIAS}

BECKER, B. Revisão das políticas de ocupação da Amazônia: é possível identificar modelos para projetar cenários? Parcerias Estratégicas, Brasília, n. 12, p. 135-159, 2001.

Amazônia. São Paulo: Ática, 1990.

CASTRO, E. Urbanização, pluralidade e singularidades das cidades amazônicas. In: (Org.). Cidades na floresta. São Paulo: Anablume, 2008. p. 13-39.

CORRÊEA, R. L. A rede urbana brasileira e a sua dinâmica: algumas reflexões e questões. In: SPOSITO, M. E. (Org.). Urbanização e cidades: perspectivas geográficas. Presidente Prudente: UNESP, 2001. p 359-367.

. Reflexões sobre a dinâmica recente da rede urbana brasileira. In:

ENCONTRO DA ASSOCIAÇÃO NACIONAL DE PÓS-GRADUAÇÃO EM PLANEJAMENTO URBANO E REGIONAL, 9. 2001. Rio de Janeiro. Anais... Rio de Janeiro, 2001, p. 424-430.

A periodização da rede urbana da Amazônia. Revista Brasileira de Geografia, Rio de Janeiro, v. 4, n.3, p. 39-68, jul./set. 1987.

CORDEIRO, E. C.; DINIZ, J. S. Região Metropolitana da Grande São Luís: além da retórica municipalista, o que serve como entrave para sua "efetivação"? In: JORNADA INTERNACIONAL DE POLÍTICAS PÚBLICAS, QUESTÃO SOCIAL E DESENVOLVIMENTO NO SÉCULO XXI, 3. 2007. São Luís. Anais... São Luís, 2007. Não paginado.

DAVIDOVICH, F. "A volta da metrópole” no Brasil. In: RIBEIRO, L. C. Q. Metrópoles: entre a coesão e a fragmentação, a cooperação e o conflito. São Paulo: Perseu Abramo, 2004. p. 197-231.

GOUVÊA, R. A questão metropolitana no Brasil. Rio de Janeiro: FGV, 2005. 
LIMA, M. C. A metropolização da Amazônia ocidental: região metropolitana de Manaus e a especificidade do urbano na Amazônia. In: SEMANA DE PÓSGRADUAÇÃO EM GEOGRAFIA HUMANA, 2. 2009. São Paulo. Anais... São Paulo, 2009. Não paginado.

MACHADO, L. O. Urbanização e mercado de trabalho na Amazônia brasileira. Cadernos IPPUR, Rio de Janeiro, v. 13, n.1, p.109-138, jan./jul. 1999.

NOGUEIRA, R. J. B. Política e território: invenção de uma região metropolitana. Revista Percurso: Sociedade, Natureza e Cultura, Curitiba, n.1, p. 179-197, 2002. OLIVEIRA, J. A. Manaus: transformações e permanências, do forte à metrópole regional, porta de entrada da Amazônia. In: CASTRO, E. (Org.). Cidades na floresta. São Paulo: Anablume, 2008. p. 59-98.

RIBEIRO, M. A. A rede urbana amazônica: da rede dendrítica à configuração de uma rede complexa. In: Urbanização e cidades: perspectivas geográficas. Presidente Prudente: UNESP, 2001. p 369-389.

RIVAS, A.; MACHADO, J. A. C. Impacto virtuoso do Polo Industrial de Manaus sobre a proteção da floresta amazônica: discurso ou fato? Manaus: Instituto PIATAM, 2009.

SANTOS, F. R. G.; MENDES, R. O. A organização do espaço urbano de São Luís e suas consequências ante o implemento dos grandes projetos econômicos/ tecnológicos em seu território. In: JORNADA INTERNACIONAL DE POLÍTICAS PÚBLICAS, 2. 2005. São Luís. Anais... São Luís, 2005. Não paginado.

SANTOS, M. A urbanização brasileira. São Paulo: Hucitec, 1993.

SATHLER, D.; MONTE-MOR, R.; CARVALHO, J. A. M. As redes para além dos rios: urbanização e desequilíbrios na Amazônia brasileira. Nova Economia, Belo Horizonte, n. 19. v. 1, p. 11-39, 2009.

TRINDADE JR. S. C. C. Cidades na floresta: os "grandes objetos" como expressões do meio técnico-científico informacional no espaço amazônico. Revista do Instituto de Estudos Brasileiros, São Paulo, n. 50, p. 13-137, 2010.

A cidade dispersa: os novos espaços de assentamentos em Belém e a reestruturação metropolitana. 1998. Tese (Doutorado em Geografia) - Faculdade de Filosofia, Letras e Ciências Humanas, Universidade de São Paulo, São Paulo, 1998.

VELOSO, T. Fronteiras de papel: análise da perspectiva metropolitana em planos diretores da Região Metropolitana de Belém. 2010. Dissertação (Mestrado em Geografia) - Instituto de Filosofia e Ciências Humanas, Universidade Federal do Pará, Belém, 2010. 